\title{
Histomorphometric Evaluation of New Bone Formation in Diabetic Rats Submitted to Insertion of Temporary Implants
}

\author{
Cyro Eduardo de Carvalho OTTONI \\ Renato Paulo CHOPARD \\ Department of Anatomy, Biomedical Sciences Institute, University of São Paulo, São Paulo, SP, Brazil
}

\begin{abstract}
This study aimed to quantify new bone formation in the femurs of diabetic Wistar rats. Over an eight-week period, MTI-MP ${ }^{\circledR}$ implants were evaluated in control rats and in diabetic rats. At several points during this period, various markers for bone deposit were introduced. The material was observed under fluorescent light microscopy. New bone formation in periosteal and cortical regions linked to the implant did not vary significantly between the groups. However, there were significant differences in total new bone formation in the medullar canal and in bone/implant contact area in the medullar portion. Bone deposits attached to the surface of the temporary implants demonstrated that they are biocompatible and capable of osseointegration.
\end{abstract}

Key Words: diabetic rats, bone formation, temporary implants.

\section{INTRODUCTION}

During the evaluation of the implant odontological techniques, it was found that some patients face an unpleasant situation, in which they are partially or even totally deprived of their prosthesis during the postimplantation cicatrization period. In light of this, this study investigated the idea of installing pillars (implants) for temporary use. These pillars fix a temporary prosthesis until completion of the osseointegration period for the 'definitive' or 'permanent' implants. Once the implants have served their purpose, they are removed. Their installation is performed concurrently with the permanent implant surgery. The osseointegration of these implants and their support of the functional load have been demonstrated in various clinical and histological studies (1-7).

Another problem faced by professionals is that the therapeutic use of implants is often contraindicated. Patients suffering from diabetes mellitus are at a higher risk for post-surgical infection and typically present lower cicatrization rates (8). Therefore, the use of implants is not recommended for these patients $(9,10)$. Most studies suggest that implants may be used in diabetic patients, but only when their illness is well under control. It is therefore necessary to administer metabolic compensation and postpone surgery until ideal conditions exist $(11,12)$.

\section{MATERIAL AND METHODS}

All experimental procedures were carried out in accordance with the ethical principles set forth by the Brazilian School of Animal Experimentation (COBEA) and with the approval of the Ethics Committee for Animal Experimentation (CEEA) of the Biomedical Sciences Institute of the University of São Paulo (ICBUSP).

In this study, ten Wistar (Rattus norvegicus) rats, weighing an average of $265 \mathrm{~g}$ each, were maintained in the animal facilities of the Anatomy Department of ICB-USP. The animals were maintained on a dark/light cycle $(12 / 12 \mathrm{~h})$ under control conditions of temperature $\left(21^{\circ} \mathrm{C}\right)$, air recycling and water and chow (Nuvilab $\left.{ }^{\mathrm{TM}}\right)$

Correspondence: Dr. Renato Paulo Chopard, Departamento de Anatomia, Instituto de Ciências Biomédicas, Universidade de São Paulo, Av. Lineu Prestes 2415, 05508-900 São Paulo, SP, Brasil. Tel +55-11-3815-9695. e-mail: rchopard@usp.br 
ad libitum. These animals were divided into 2 groups. One group was used as the control, and, seven days prior to the surgical intervention, the other group was induced to a diabetic condition by endovenous injection of alloxan in a single dose of $30 \mathrm{mg} / \mathrm{kg}$ of body weight. Blood glucose levels of the animals were evaluated weekly. Blood samples were collected from the distal third of the tail from each animal and measured by the glycosis-perioxidase method by a digital glycosimeter (Advantage Blood Glucose Monitor ${ }^{\mathrm{TM}}$, Boehringer Mannheim Corporation, Ingelheim, Germany), whose detection limits ranged from 10 to $600 \mathrm{mg} / \mathrm{dl}$. Only those animals in which glucose levels were maintained at $300 \mathrm{mg} / \mathrm{dl}$ or higher throughout the entire experimental period were considered diabetic.

Modified MTI-MP ${ }^{\circledR}$ (Dentatus AB, Stockholm, Sweden) implants were used. The MTI-MP ${ }^{\circledR}$ implants are made from pure titanium, threadable and for temporary use. The implants originally measured $1.3 \mathrm{~mm}$ in internal diameter, $1.5 \mathrm{~mm}$ in external diameter and 14 $\mathrm{mm}$ in length. However, for the purpose of this study, the length of each implant was reduced to $5 \mathrm{~mm}$. Subsequently, the implants were sterilized in an autoclave.

Cetamine chlorhydrate at a dose of $80 \mathrm{mg} / \mathrm{kg}$ was used for anesthesia. For muscular relaxation, sedation and analgesia, 2\% xylazine hydrochloride was used (12 $\mathrm{mg} / \mathrm{kg}$, ip, single dose). Under anesthesia, three implants were inserted into the antero-lateral side of diaphysis in the left femurs of the animals, maintaining a distance of approximately of $5 \mathrm{~mm}$ between implants. In order to achieve parallelism between the elements, the insertion axis of each implant was perpendicular to the long axis of the receptor bone. The implantation beds were prepared using the drills indicated by the manufacturer assembled at a surgical contra-angle, running at approximately $1500 \mathrm{rpm}$ and abundantly irrigated with saline solution. In the immediate postoperative period, benzylpenicillin benzatin $(0.06 \mathrm{ml} / \mathrm{kg}$, im, single dose $)$ and paracetamol $(10 \mathrm{mg} / \mathrm{kg}$ in drops diluted in the water for consumption for 2 consecutive days and changed daily) were administered. The cicatrization period was 8 weeks. During this period, a fluorescent marker was administered weekly $(10 \mathrm{mg} / \mathrm{kg}$ calcein diluted in a $2 \% \mathrm{NaHCO}_{3}$ solution).

On day 56 after surgery, the animals were submitted to euthanasia with an overdose of ketamine chlorohydrate $(300 \mathrm{mg} / \mathrm{kg})$. The soft tissues were dis- sected and the femurs were isolated. These were fixed in formalin for 30 days. Each sample was subjected to periapical radiography of the pellicle (odontological use), with a perpendicular incidence on the anteromedial side. The position of each implant was confirmed and the transversal cuts were made in order to obtain individual blocks.

After routine histological processing, the blocks were immersed in containers filled with historesin (methyl methacrylate $-\mathrm{C}_{5} \mathrm{H}_{8} \mathrm{O}_{2}$ ) for inclusion. Transversal cuts, longitudinal to the implants, were then made with a microtome. The resulting sections were assembled on glass slides, ground down to an average thickness of $200 \mu \mathrm{m}$ and examined under fluorescent light microscopy.

To perform the histomorphometric analysis, a millimeter grid was placed on the $20 \times 25$-cm amplifications of the obtained images. By counting the filled box from each target, the proportion of osseous neo-formation related areas characterized by the marker was quantified (13). It was necessary to categorize the various regions of the sections. In the areas of the bone cortex and medullar canal, the implant sections were subdivided into head, intra-cortical or intra-medullar portions (Figure 1).

The following relations were evaluated:

1. Total percentage of new bone formation $(\mathrm{TNbF})$ in the entire section:

$$
T N b F\left(\text { in \%) }=\frac{\text { Total area of marker X } 100}{\text { Total bone area of the section }}\right.
$$

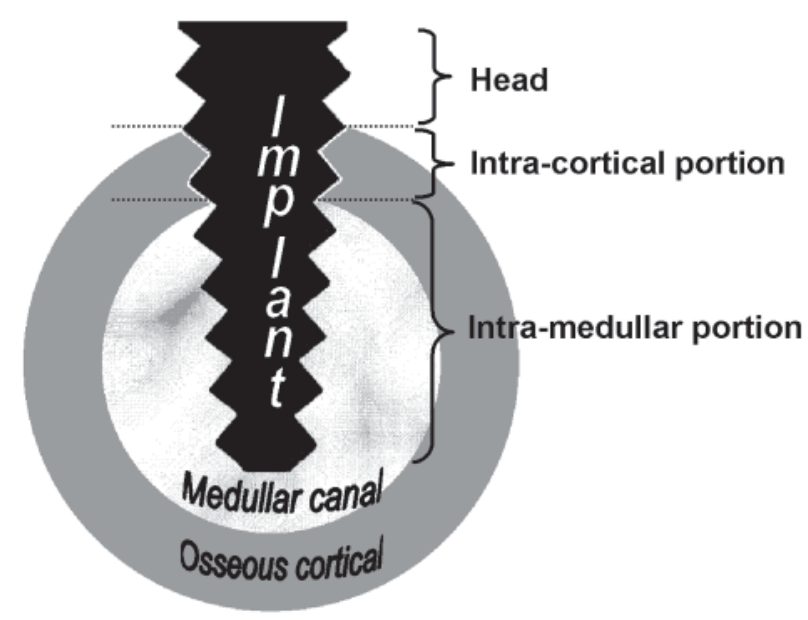

Figure 1. Subdivisions of the implant sections. 
2. Percentage of new bone formation linked to the periosteal side $(\mathrm{NbFP})$ in the entire section:

NbFP (in \%) = Area of marker on the periosteal side $X 100$

Total bone area of the section

3. Percentage of new bone formation linked to the endosteal side and in the medullar canal (NbFMC):

NbFMC (in \%) = Area of marker on the endosteal side and in the medullar canal X 100

Total bone area of the section

4. Percentage of contact between bone and implant on the intra-cortical side (BIpCC)

BIpCC (in \%) = Perimeter of bone/implant contact on the intra-cortical side X 100

Perimeter of the implant on the intra-cortical side

5. Percentage of contact between bone and implant in the intra-medullar portion (BIpCM)

BIpCM (in \%) = Perimeter of bone/implant contact in the intra-medullar portion $X 100$

Perimeter of implant in the intra-medullar portion

6. Percentage of total contact between new bone formation and implant (TNbIC)

TNbIC (in \%) = Perimeter of the bone/implant contact in intra-cortical and intramedullar portions $X 100$

Total perimeter of implant in intracortical and intra-medullar portion

The statistical analysis was performed using analysis of variance by non-paired T test and ANOVA with specific softwear (GraphPad InStat - Version 3.00, GraphPad Software Inc., San Diego, CA, USA).

\section{RESULTS}

Under fluorescent light microscopy, it was possible to observe the presence of markers and, therefore, the occurrence of bone deposit. In descending order of quantity, the three markers observed were calcein, tetracycline and alizarin. In this analysis, it was also possible to distinguish the bone tissue as (4): a) primary bone: the cortical tissue already present at the time of the surgery. This tissue was not identified by the mark- ers; b) secondary bone: bone that appears after the introduction of the implants. The markers identified apatite crystal deposits. It was possible to observe bands of different colors corresponding to the administration of each stain.

\section{Control Group}

Analysis of the sections revealed intense new bone formation. This was verified in a generalized way, encompassing the periosteal, endosteal and medullar canal regions of all samples.

The new bone formation presented lamellar characteristics. In the periosteal regions, layered deposits of new bone formation of various thicknesses were observed. The most common deposits were those marked by calcein, which were characterized by the formation of two parallel lamellae coinciding with the two periods during which this marker was administered. The other markers did not present this same characteristic.

In the endosteal region, new bone formation was less evident than in the periosteal region. Bone deposits were frequently observed running along the entire surface of implants. Formation of a trabecular pattern spreading over the medullar canal, with bone bridges connecting the endosteum to the implant surface, was also observed.

\section{Diabetic Group}

Analysis of this group showed new bone formation in all implants. In a general way, the area of new bone formation was significantly smaller than in the control group. However, new bone formation in the periosteal region was comparable to that observed in the control group.

In all samples, new bone formation that followed exactly the surface of the implant was observed. The frequently observed bone bridges linking the endosteum to the surface of the implant in the control group only appeared in 2 of 9 implants in this group (Figure 2).

\section{Morphometric Analysis}

Values of $\mathrm{p}<0.05$ were considered significant for statistical analysis. To determine whether the position of the implant resulted in any difference among the results obtained from a given animal, the data were 

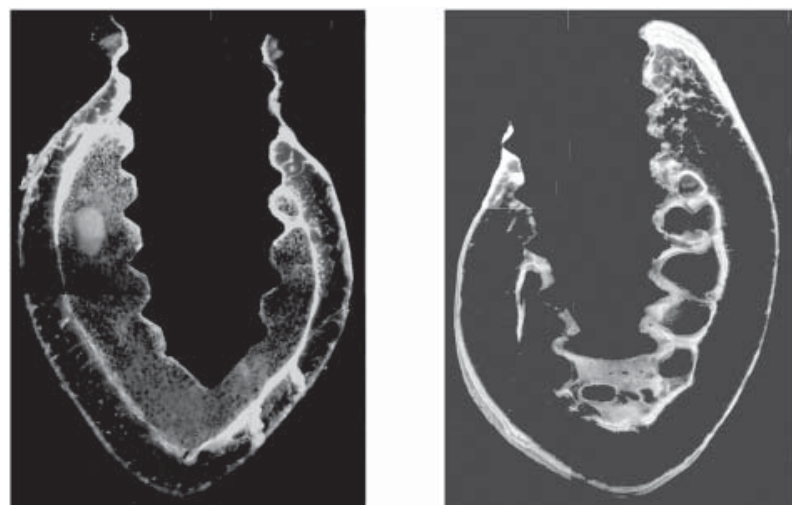

Figure 2. Bone bridges linking the endosteum to the surface of the implant.

Table 1. Comparison of new bone formation in control and diabetic groups

\begin{tabular}{lcc}
\hline Relationship & Control & Diabetic \\
\hline $\mathrm{TNbF}$ & $44.93 \pm 2.714$ & $37.35 \pm 5.019^{*}$ \\
$\mathrm{NbFP}$ & $28.14 \pm 4.512$ & $25.18 \pm 4.091$ \\
$\mathrm{NbFMC}$ & $43.76 \pm 13.976$ & $17.87 \pm 3.744^{*}$ \\
$\mathrm{BIpCC}$ & $70.81 \pm 11.848$ & $78.13 \pm 11.276$ \\
$\mathrm{BIpCM}$ & $73.03 \pm 14.516$ & $39.00 \pm 11.606^{*}$ \\
$\mathrm{TNbIC}$ & $71.56 \pm 10.377$ & $49.18 \pm 10.056^{*}$ \\
\hline
\end{tabular}

Data are reported as mean $\pm \mathrm{SD} . *$ Significant difference between control and diabetic groups (unpaired $t$-test, $\mathrm{p}<0.05$ ).

$\mathrm{TNbF}$, total new bone formation; $\mathrm{NbFP}$, new bone formation on the periosteal side; $\mathrm{NbFMC}$, new bone formation in the medullar canal; BIpCC, bone/implant contact in the cortical region; BIpCM, bone/implant contact in intra-medullar portion; TNbIC, total new bone formation/implant contact.

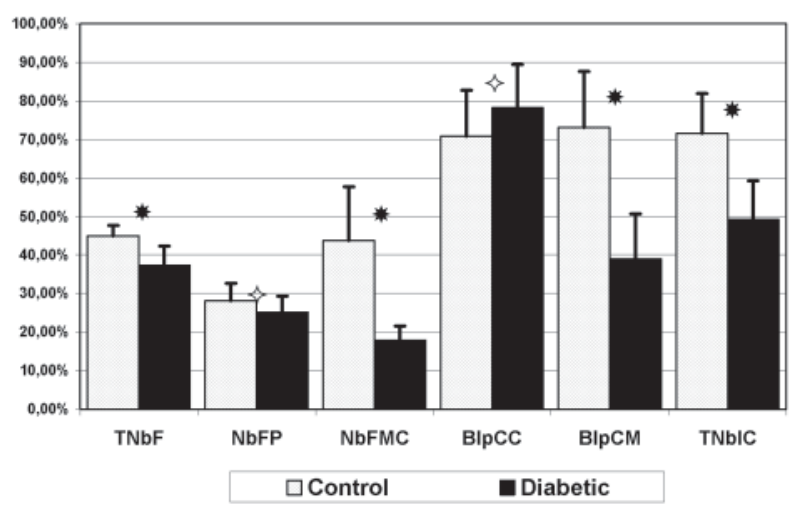

Figure 3. Comparison of new bone formation in control and diabetic groups. See text and legend to Table 1 for explanation of abbreviations. submitted to ANOVA, which revealed that the introduction of implants had no influence on new bone formation in any group $(\mathrm{p}>0.05)$.

Data were then submitted to an unpaired $t$-test for comparison of the proposed relationships between findings from the control group and those from the diabetic group (Table 1 and Figure 3).

\section{DISCUSSION}

In samples from control and diabetic groups, the fluorescent markers revealed bone formation activity, as well as intense osteogenic activity, that was distributed in adjacent sections and varied depending upon the region observed. The calcein marker produced the most pronounced results, followed by the tetracycline and alizarin markers, in that order. Through qualitative analysis, we confirmed that the period of highest osteogenic activity was at the beginning of the $4^{\text {th }}$ week and at the end of the $5^{\text {th }}$ week. In contrast, a small deposit of alizarin led us to conclude that little activity occurred during the initial period of study ( $2^{\text {nd }}$ and $3^{\text {rd }}$ weeks).

Constant new bone formation was observed, regardless of the region or group studied in agreement with findings from other research. Bone deposits were seen in the periosteal and endosteal regions, as well as in the interior medullar canal and on the implant surface (15-17).

In the present study, the system of temporary implants used (MTI-MP ${ }^{\circledR}$ ) showed characteristics of osseointegration with a median of $71.56 \% \pm 10.377$ $\mathrm{TNbIC}$, which is higher than the $45 \%$ found in previous studies (6). However, it is important to bear in mind that this study was performed with human material from areas where the implants had been under a masticatory load immediately following introduction of the implant, possibly accounting for these differences. The bone/implant contact values reinforce previous clinically obtained results (3-7). The rate of contact between bone and implant was equivalent to that found for implants designed for long-term use.

In the histomorphometric analysis, the head region was omitted, despite the new bone formation that had been observed in this area. This was justified by the fact that the new bone formation in this region is attributable more to the surgical technique than to the osteoconductive properties of the implant. After the periosteum has been dislocated, folded over, replaced 
and sutured, a subperiosteal space is formed that ends up being a place for formation and retention of blood clots. Later, it is replaced by bone.

Examination of the material under fluorescent light microscopy employing a prism revealed a clear difference in the new bone formation observed in the medullar canal, which normally presents no calcified tissue. After introduction of the implants, bone with lamellar characteristics was observed in the medullar canal. This bone deposit presented trabecular morphology, forming bone bridges linking the endosteum to the surface of the implant or running the length of the implant. In addition, in the qualitative analysis, welldefined formations were observed in samples from control group animals, whereas no such formations were seen in the diabetic group.

An extremely significant statistical difference was found between the two groups in the percentage of new bone formation in TNbIC. This is in agreement with the findings of other authors $(16,18)$. A similarly significant difference has been shown during the cicatrization period, at 14 days and 84 days post-implantation $(15,18)$. In these previous studies, the animals in the diabetic groups received no diabetic control.

The values obtained for BIpCM were extremely significant, similar to those from other studies $(15,16)$. Analysis of the TNbIC revealed increased new bone formation in comparison with the control group; however, the differences between the groups remain significant (17). Comparison of BIpCC values showed a nonsignificant difference (15).

For the other relationships evaluated in the present study, the results were not in agreement with those reported by other authors. Comparing new bone formation data from the different regions, we can conclude that metabolic alterations resulting from clinical diabetic conditions led to lower osteogenic activity. This phenomenon has been previously described $(15,17,19-$ 20).

The initial expectation of the authors of the present study was that there would be a generalized reduction in bone deposit. The non-significant difference in $\mathrm{NbFP}$ and BIpCC between the two groups was a surprising finding. We can hypothesize that the surgical trauma caused by rotation, cutting or heating (despite the care in irrigation) of the area during the creation of the implantation beds stimulated a cicatrization process different from that typically promoted by the osteoconductive characteristics of titanium. On the other hand, considering the deposit in the periosteal side, this finding may be attributable to the apposition phenomenon that occurs during normal bone formation. Therefore, this may occur independently of the introduction of the implant. All other regions evaluated were created as a result of the installation of the implants.

Thus, the bone deposits attached to the surface of temporary implants demonstrated that they are biocompatible and capable of osseointegration.

\section{RESUMO}

Este estudo se propôs a quantificar a neoformação óssea nos fêmures de ratos Wistar diabéticos. Implantes MTI-MP ${ }^{\circledR}$ foram avaliados por um período cicatricial de 8 semanas durante as quais foram administrados marcadores de deposição óssea. O material foi observado sob microscopia de luz fluorescente. A neoformação óssea nas regiões periostal e na cortical junto ao implante não mostraram diferença significativa entre os grupos. Essa mostrou-se significativa quando avaliado o canal medullar, na avaliação do tecido neoformado como um todo e na área de contato entre osso e implante quando analisada sua porção intramedullar. A deposição óssea analisada junto à superfície dos implantes temporários demonstrou que os mesmos são biocompatíveis e passíveis de osteointegração.

\section{REFERENCES}

1. Brånemark PI, Breine U, Adell R, Hansson BO, Indströn J, Olsson A. Intraosseous anchorage of dental protheses. I. Experimental studies. Scand J Plast Reconstr Surg 1969; 3:81-85.

2. Adell R, Lekholm U, Rockler B, Brånemark PI. A 15-year study of osseointegrated implants in the treatment of the edentulous jaw. Int J Oral Surg 1981;10:387-416.

3. Petrungaro PS, Windmiller N. Using transitional implants during the healing phase of implant reconstruction. Gen Dent 2001;49:46-51.

4. Froum S, Emtiaz S, Bloom MJ, Scolnick J, Tarnow DP. The use of transitional implants for immediate fixed temporary prostheses in cases of implant restorations. Pract Periodontol Aesthet Dent 1998; 10:737-746.

5. el Attar MS, el Shazly D, Osman S, el Domiati S, Salloum MG. Study of the effect of using mini-transitional implants as temporary abutments in implant overdenture cases. Implant Dent 1999;8:152-158.

6. Bohsali K, Simon H, Kan JYK, Redd M. Modular transitional implants to support the interim maxillary overdenture. Compendium 1999;20:975-983.

7. Nagata M, Nagaoka S, Mukunoki O. The efficacy of modular transitional implants placed simultaneously with implant fixtures. Compendium Contin Educ Dent 1999;20:39-42.

8. Goodson WH, Hunt TK. Wound healing and the diabetic patient. Surg Gynecol Obstet 1979;49:600-608.

9. Shapiro SA. Discussion of alveolar bone physiology relative to implants for the elderly. ODA J 1992;Fall:33-37. 
10. Smith RA, Berger R, Dodson TB. Risk factors associated with dental implants in healthy and medically compromised patients. Int J Oral Maxillofac Implants 1992;7:367-372.

11. Balshi TJ, Wolfinger GJ. Dental implants in the diabetic patient: a retrospective study. Implant Dent 1999;8:355-359.

12. Askary AS, Meffert RM, Griffin T. Why do dental implants fail? Part I. Implant Dent 1999;8:173-185.

13. Schenk RK, Olah A. Histomorphometrie. In: Kuhlencordt S, Bartelheimer H. eds. Handbuch der Innerem Medizin. Berlin: Springer Verlag, 1980, p 337-393.

14. König BJ, Beck TJ, Kappert HF, Kappert CC, Masuko TS. A study of different calcification areas in newly formed bone 8 weeks after insertion of dental implants in rabbit tibias. Ann Anat 1998;180:471-475.

15. McCracken M, Lemons JE, Rahemtulla F, Prince CW, Feldman D. Bone response to titanium alloy implants placed in diabetic rats. Int J Oral Maxillofac Implants 2000;15:335-353.
16. Nevins ML, Karimbux NY, Weber HP, Giannobile WV, Fiorellini JP. Wound healing around endosseous implants in experimental diabetes. Int J Oral Maxillofac Implants 1998;13:620-629.

17. Fiorellini JP, Nevins ML, Norkin A, Weber HP, Karimbux NY. The effect of insulin therapy on osseointegration in a diabetic rat model. Clin Oral Impl Res 1999;10:362-368.

18. Takeshita F, Murai K, Iyama S, Ayukawa Y, Suetsugu T. Uncontrolled diabetes hinders bone formation around titanium implants in rat tibiae. A light and fluorescence microscopy, and image processing study. J Periodontol 1998;69:313-320.

19. Gerritsen M, Lutterman JA, Jansen JA. Wound healing around bone-anchored percutaneous devices in experimental diabetes mellitus. J Biomed Mater 2000;53:702-709.

20. Giglio MJ, Giannunzio G, Olmedo D, Guglielmotti MB. Histomorphometric study of bone healing around laminar implants in experimental diabetes. Implant Dent 2000;9:143-149.

Accepted April 25, 2004 